\title{
Intuiciones de criptojudaísmo en el Quod nihil scitur de Francisco Sánchez.
}

\author{
A glimpse of Jewish thought in Francisco \\ Sánchez's Quod nihil scitur
}

\author{
MANUEL BERMÚDEZ VÁZQUEZ \\ Universidad de Córdoba
}

Recibido: 06-02-2007 Aprobado definitivamente: 22-02-2007

RESUMEN

En la obra del pensador gallego Francisco Sánchez (1551-1623), titulada Que nada se sabe, existen una serie de características que nos obligan a relacionarla directamente con el pensamiento judío. Entre estas cuestiones se hallan: las citas bíblicas recogidas por su autor, siendo la gran mayoría de ellas procedentes del Antiguo Testamento; la falta de la dedicatoria a la virgen María o la relación entre el alma y el cuerpo que recoge Sánchez y que es de claro origen judío.

\section{PALABRAS CLAVE}

ESCEPTICISMO, PENSAMIENTO JUDÍO, FRANCISCO SÁNCHEZ

\begin{abstract}
In the work of the thinker Francisco Sanchez (1551-1623), entitled That nothing is known, there are some characteristics that force us to directly relate it to the Jewish thought. Some of these questions are: the Biblical quotations gathered by its author, coming the great majority of them from the Old Testament; the lack of the dedication to Virgin Mary or the relation between the soul and the body that Sanchez shares with the Jewish tradition. All these topics point at the importance of this tradition in the work That nothing is known.
\end{abstract}

KEYWORDS

SCEPTICISM, JEWISH THOUGHT, FRANCISCO SANCHEZ, RENAISSANCE

(C) Contrastes. Revista Internacional de Filosofía, vol. XIII (2008), pp. 285-294. ISSN: 1136-4076

Licenciatura de Filosofía, Universidad de Málaga, Facultad de Filosofía y Letras

Campus de Teatinos, E-29071 Málaga (España) 
La biografía de Francisco Sánchez (Tuy 1551-Toulouse 1623) ha estado plagada de incógnitas que la moderna historiografía ha ido resolviendo. Comenzando por su lugar de nacimiento y terminando por el año de su muerte, la mayor parte de las fechas significativas en la trayectoria vital de este médico y filósofo gallego estaban sumidas en la oscuridad de la duda. Sin embargo, muchas de estas cuestiones se han determinado recientemente: hemos podido establecer que Sánchez nació en 1551, en Tuy, Galicia, fue bautizado en la diócesis de Braga -de aquí procede la larguísima polémica con los eruditos lusos que teorizaban sobre su origen portugués-, procedía de una familia de judíos conversos, vivió en Burdeos, Montpellier, Italia y Toulouse y murió en esta última ciudad en $1623 .{ }^{1}$

Todas estas consideraciones biográficas podrían quedar fuera de cualquier análisis estrictamente filosófico si no fuera porque consideramos que una de ellas marcó la trayectoria de la obra filosófica del tudense. Esta incógnita tan importante fue la ascendencia judía de Francisco Sánchez, cuestión que, por estar inserta en lo más íntimo del sentimiento religioso e intelectual del individuo, nunca puede ser establecida completamente si el personaje no se ha declarado abiertamente sobre ello. Y el caso que nos ocupa aquí es que Francisco Sánchez nunca se mostró a sí mismo como un judío converso, ni en su vida ${ }^{2}$ ni, prácticamente, en su obra. Al menos esto último puede parecer tras un análisis somero de los escritos filosóficos del tudense. Sin embargo, el objeto del presente artículo es esclarecer que, muy probablemente, en los trabajos intelectuales iniciales de Francisco Sánchez, existía un elemento muy importante de ascendencia judaizante producto de su origen familiar converso.

Sánchez procedía de una importante familia de judíos conversos que venía de Aragón y que ocupó, en tiempos del rey Fernando el Católico, un puesto administrativo de gran importancia. Sus antepasados familiares, probablemente, tuvieron algo que ver con los sucesos de la conspiración de Zaragoza que acabó con el asesinato de un fraile y un canónigo de la catedral, que tenían sobre sus hombros la responsabilidad de instalar el Tribunal del Santo Oficio en Aragón. Después de esto, la familia emigró a Galicia, eligiendo preferentemente los lugares fronterizos como Tuy por sus ventajas obvias de lugar de mayor tolerancia y enclave de comunicaciones con fácil huida en caso de necesidad. ${ }^{3}$

1 Toda esta información queda consignada en M. Bermúdez La recuperación del escepticismo en el Renacimiento como propedéutica a la filosofía de Francisco Sánchez, Córdoba, 2005, tesis doctoral.

2 Valga como ejemplo la opinión del importante erudito portugués Joaquim de Carvalho, para quien Sánchez "aunque nació como cristiano nuevo, en su conducta y actitudes parecía un cristiano viejo”, véase J. de Carvalho, Francisco Sanches: Opera philosophica, Coimbra, 1955 , p. ix.

3 Sobre los detalles biográficos de Sánchez véase M. Bermúdez, op. cit., capítulo 3. 
También podemos señalar que entre Sánchez y Michel de Montaigne existía un lejano parentesco, ${ }^{4}$ lo cual no deja de ser una sorprendente coincidencia que dos de los mayores exponentes del escepticismo renacentista procedieran del entorno judío.

La tesis fundamental que venimos a defender en el presente trabajo es que Francisco Sánchez presentaba durante sus primeros años de madurez una mayor ascendencia e influencia del mundo judío, proveniente todo esto de su formación familiar y de los años pasados en el colegio de la Guyenne. Los datos que ofrecemos para avalar esta idea son de gran claridad.

Primero. La familia de Francisco Sánchez había sido judía ${ }^{5}$ y sólo una generación antes de nuestro autor seguían practicando la religión de Abraham. Como aparece evidente, la religión no es una cuestión que pueda dejarse de lado sencillamente así como así, sobre todo cuando la necesidad es la que obliga a cambiarla y no una cuestión de fe. La presión social obligó a muchos conversos a practicar la religión católica de forma pública, pero lo que ocurriera de puertas a dentro de los hogares quedaba en secreto. Resulta imposible, evidentemente, determinar cuál era el sentido de las creencias religiosas de la familia de Sánchez, pero no parece una especulación aventurada sugerir que quizá parte de las enseñanzas que los padres inculcaron a sus hijos fueran de origen judío. Es más, probablemente la cultura hebrea fue una fuente importante en la educación del filósofo gallego por cuanto al abandonar la península ibérica la familia se dirigió a Francia, concretamente a Burdeos. Burdeos era, por aquella época, un lugar de acogida de numerosos judíos de toda Europa. Era una ciudad caracterizada por su atmósfera abierta, tolerante y liberal. Allí se matricula en el célebre colegio de la Guyenne. El colegio de la Guyenne era una entidad patrocinada por individuos del entorno judío o cristianos nuevos a los que, muy probablemente, mantenía unidos el sentimiento de formar parte de una misma casta, si bien no vamos a elucubrar con que mantuvieran ningún tipo de actividad relacionada con el llamado «espíritu judaico». Sin embargo, algunas de las características que definen este espíritu judío estaban presentes en el pensamiento de Francisco Sánchez, como por ejemplo las tendencias reservadas, una actitud un tanto suspicaz y ausente de patriotismo, ${ }^{6}$ así como cierto desapego por las costumbres cristianas.

Segundo. Establecido, pues, que la educación de Francisco Sánchez estuvo determinada, en mayor o en menor medida, por la ascendencia judía de

4 El padre de Francisco Sánchez se llamaba Antonio Sánchez y su cuñado, Antonio López, fue cuñado del padre de Montaigne. Cfr. Fortunat Strowski, Montaigne, París, 1931, p. 136.

5 Cfr. J. de Carvalho, op. cit., pp. viii-ix, nota 4.

6 Sánchez firmó la matrícula de la universidad de Toulouse como tudense, sin embargo no le importaba que sus compañeros de esta misma universidad pusieran en su retrato que era lusitano. Véase C. Mellizo, Nueva introducción a Francisco Sánchez, Zamora, 1982, p. 12, n. 3. 
su entorno, planteamos ahora otra cuestión no menor y que vuelve a situar al tudense en la órbita del criptojudaísmo: las dos primeras obras importantes de Sánchez, tanto el Quod nihil scitur como el Carmen de cometa no contienen la alabanza a la virgen con la que se cerraban la mayoría de las obras de la época. ${ }^{7}$ Sin embargo, este Laus deo virginique Mariae no falta en el resto de sus obras. Un asunto así no puede ser baladí porque esta alabanza mariana tenía su importancia y, evidentemente, no cabe la posibilidad de que el autor no lo hiciera con alguna intencionalidad o significación.

Estas dos obras son de un periodo temprano en la evolución y maduración intelectual de Sánchez, el Quod nihil scitur ${ }^{8}$ fue publicado en 1581, aunque el propio autor reconocía haberlo escrito unos siete años antes, alrededor del año $1574,{ }^{9}$ mientras que el Carmen de cometa es una obra del año 1578. Probablemente en este periodo es cuando más fuertemente se reflejaban las influencias judaizantes de la formación del tudense en su obra. El ascendiente tanto de su padre, Antonio Sánchez, como de su tío, Adán Francisco, se mostraba, así, de una forma más palpable.

Tercero. Existe un nexo de unión entre esta influencia del mundo criptojudío en Sánchez y su orientación escéptica, plasmado de forma directa en su obra fundamental Que nada se sabe (Quod nihil scitur). Con gran probabilidad la mentalidad surgida de este espíritu judaico sugería la opción escéptica como la más adecuada por sus características de crítica constante sin aferrarse a ninguna afirmación dogmática, de ahí que un individuo como Michel de Montaigne, que recibió una influencia semejante en su infancia, derivara parte de su pensamiento hacia el escepticismo en alguna parte de su obra como es el caso de la Apología de Ramón Sibiuda. El pensamiento de origen hebreo tendría cabida en la obra de Francisco Sánchez en la medida en que algunas de sus ideas se prestan para ser utilizadas en la negación de la posibilidad del conocimiento, que es el objetivo polémico del tudense. ${ }^{10}$

Antes de pasar al análisis básico de este artículo, que consiste en el estudio de las citas bíblicas aparecidas en el Que nada se sabe como prueba fehaciente de la influencia del mundo judío en el pensamiento de Sánchez, hemos de señalar que la postura filosófico-religiosa del tudense cambió considerablemente a lo largo de los años. Es esta evolución la que nos muestra claramente cómo

7 Cfr. J. Faur, In the shadow of history, Nueva York, 1992, pp. 93-94.

8 Para las citas del Quod nihil scitur (Que nada se sabe) utilizaremos la edición del Consejo Superior de Investigaciones Científicas, Francisco Sánchez, Quod nihil scitur, edición y traducción de S. Rábade, J. M. Artola y M. F. Pérez, Madrid, 1984. En adelante indicaremos Q.N.S. más el número de la página de la edición del CSIC.

9 Véase Q.N.S., p. 48.

10 Sobre los objetivos del Quod nihil scitur véase M. Bermúdez, op. cit., pp. 182-183 y también pp. 390-99. 
Sánchez pasó a ser, probablemente, un católico convencido en su madurez, tras haber titubeado su fe en los primeros años de su madurez intelectual. Las razones que nos llevan a pensar esto son que el tudense permitió a dos de sus hijos que se dedicaran al sacerdocio y la alabanza a la virgen María no volvió a faltar en sus obras a partir de la década de 1580. Entre los motivos que podemos señalar para este cambio están la persecución a la que Sánchez se vio sometido en Montpellier, una ciudad bajo el dominio de los hugonotes y terriblemente intransigente hacia los católicos. Sánchez, que fue mal considerado tanto por su confesión católica como por su origen judío, probablemente sintió un mayor apego al catolicismo cuando se vio perseguido por gentes que se oponían más fuertemente a este último que a la religión de Abraham. También debió influir en Sánchez el hecho de que, una vez asentado en la comunidad de Toulouse, siendo reconocido en su labor profesional y habiéndose granjeado el prestigio y el reconocimiento de sus convecinos, el catolicismo se tornase más fuerte en su intimidad religiosa, siendo la confesión dominante en esta ciudad. Además, conforme cronológicamente nos alejamos de la influencia tanto de su padre como de su tío, es normal que Sánchez evolucionara de una forma diferente, aproximándose a la confesión católica.

En el Que nada se sabe aparecen doce citas bíblicas. De estas doce citas, tan sólo dos son parte del Nuevo Testamento, el resto, las otras diez, forman parte del Antiguo Testamento que es parte de las escrituras hebreas. Las citas de la Biblia son:

- Éxodo, capítulo 7, versículos 7-11 (Q.N.S., p. 75).

- Éxodo, capítulo 33, versículo 20 (Q.N.S., p. 117).

- Pablo a los romanos, capítulo 1, versículo 20 (Q.N.S., p. 117).

- Génesis, capítulo 2, versículos 19-20 (Q.N.S., p. 135).

- Eclesiastés, capítulo 1, versículo 48 (Q.N.S., p. 145).

- Salmos, 101-102, versículo 27 (Q.N.S., p. 145).

- Génesis, capítulo 1, versículos 1-3 (Q.N.S., p. 145).

- Éxodo, capítulo 3, versículos 2 y ss. (Q.N.S., p. 155).

- Éxodo, capítulo 14, versículo 24 (Q.N.S., p. 155).

- Hechos de los apóstoles, capítulos 2, versículo 3 (Q.N.S., p. 155).

- Eclesiastés, capítulo 1 versículo 13 y capítulo 3 versículos 10-11 (Q.N.S., p. 163).

En estas doce citas de la Biblia resaltan, fundamentalmente, dos de ellas pertenecientes al Nuevo Testamento, el resto pertenecen al Antiguo Testamento que, como hemos dicho, es una parte de las escrituras hebreas. Ahora bien, establecido este hecho, que podría parecer una cuestión lateral y no indicativa de nada, resulta que una lectura atenta de estos pasajes bíblicos junto con el contexto 
en el que se hayan insertos, arroja como resultado que las dos citas del Nuevo Testamento, una de Pablo a los romanos y otra de los Hechos de los apóstoles, son notas marginales que no tienen nada que ver con el cuerpo del texto. ${ }^{11}$ De hecho, la impresión que causan es la de haber sido dispuestas de una forma artificial y ajena a la cuestión que se está tratando en esas páginas. Esta característica produce que aún sea más conspicuo el contraste entre estos pasajes y el resto de citas bíblicas del Antiguo Testamento que sí encajan con el contenido.

Comencemos por la primera de estas dos citas, la de Pablo a los romanos, que, en nuestra opinión, fue deliberadamente dispuesta para ocultar que el tudense estaba prácticamente parafraseando una doctrina básica del corpus filosófico de Maimónides. En el pasaje en que aparece este fragmento, Sánchez estaba tratando de demostrar que nadie puede llegar a conocer a Dios perfectamente. Con este objeto cita las escrituras, concretamente Éxodo, capítulo 33, versículo 20:

Pero a Dios, ¿quién lo conoce perfectamente? «No me verá el hombre y seguirá viviendo». Por ello sólo a Moisés le fue permitido verle mediante lo que de Él se sigue, esto es, por sus obras. De ahí que dijera el otro: «Lo invisible de Dios se ve entendiéndolo a través de lo creado».12

Como aparece evidente, esta última adición del fragmento de Pablo a los romanos es forzada e incluso superflua. También es una sutil coincidencia que ésta sea una de las doctrinas básicas de Maimónides formulada en conexión con este verso bíblico. Maimónides sostenía que Moisés fue incapaz de contemplar el rostro de Dios, o lo que es lo mismo, la esencia divina, y que el encargado de recoger las tablas de la ley comprendió que Dios sólo podía ser comprendido a través de sus obras y atributos. Maimónides lo recoge de este modo en su obra Guía de perplejos:

Moisés había solicitado cierta percepción [...], y le fue prometida una de orden inferior a la suplicada por él, a saber, la designada por la expresión «ver su posteridad»[...]. Aquí se indica, pues, que Dios le veló aquella percepción [...] y le trasladó a otra cosa, cual es el conocimiento de las acciones atribuidas a Dios, que se consideran como numerosos atributos». ${ }^{13}$

11 Una parte del análisis que sigue sobre estas citas del Nuevo Testamento aparece en M. Bermúdez, «Elementos de la filosofía de Maimónides en el Quod nihil scitur de Francisco Sánchez», en Maimónides y el pensamiento medieval, IV Congreso nacional de filosofía medieval, Actas, Córdoba, 2004 (en prensa).

12 Q.N.S., p. 117. Texto latino: «Deum autem quis perfecte novit? Non videbit me homo et vivet. Proinde solum licuit Moysi videre eum per posteriora, id est, per opera sua. Unde ille, invisibilia Dei per ea quae facta sunt intellecta conspiciuntur».

13 Maimónides, Guía de perplejos, edición de David Gonzalo Maeso, Madrid, 1984, primera parte, capítulo 21, p. 93. 
La posición que está defendiendo aquí Maimónides consiste, fundamentalmente, en considerar que a Dios sólo se le puede conocer a través de sus obras y que este es el único camino para tratar de llegar a percibirlo. De hecho, la analogía entre el fragmento de Sánchez y la filosofía del judío cordobés se mostrará aún más nítidamente en otros párrafos de Guía de perplejos en los que Maimónides utiliza los mismos pasajes bíblicos que, siglos después, incluirá el tudense en su obra. Por ejemplo:

En este sentido se ha dicho: «Y me verás las espaldas» (Éxodo 33. 23), lo cual significa «aprehenderás lo que me sigue», lo que se asemeja a Mi y resulta de mi voluntad, en suma, todas mis criaturas». ${ }^{14}$

El paralelismo de los conceptos es evidente y todo esto muestra que la adición de este fragmento bíblico de Pablo a los romanos por parte de Francisco Sánchez es, cuando menos, sorprendente y, casi podríamos decir, fuera de lugar en el contexto de la explicación que se está ofreciendo. El tudense inicia el párrafo con un análisis sobre el conocimiento de los primeros principios, de una forma racional y ordenada según su estilo agudo y metódico, para luego acabar con la referencia bíblica poco acorde con el contenido:

Pues ni siquiera tienes conocimiento del primer principio y el más necesario de todos; consiguientemente, tampoco conocerás los demás, que de él se derivan [...]. Pero a Dios ¿quién lo conoce perfectamente? «No me verá el hombre y seguirá viviendo». Por ello sólo a Moisés le fue permitido verle mediante lo que de Él se sigue, esto es, por sus obras. De ahí que dijera el otro: «Lo invisible de Dios se ve entendiéndolo a través de lo creado». ${ }^{15}$

Una lectura atenta y detenida muestra perfectamente el carácter artificial de este último pasaje bíblico que muy forzadamente cabría en el contexto.

La proximidad entre Sánchez y Maimónides, arriba demostrada por las analogías incontrovertibles entre los textos, es una prueba más de la influencia de la filosofía y la tradición judías en el pensamiento del tudense.

Pasamos a abordar la cuestión de la segunda cita del Nuevo Testamento recogida en el Quod nihil scitur, una fragmento de los Hechos de los apóstoles. El marco en el que se haya incluido es al final de una larga perorata sobre el calor y su cambio constante y diversidad de efectos. Al aumentar el número de los efectos de una cosa aumenta, al mismo tiempo, su dificultad para ser

14 Idem, primera parte, capítulo 38, p. 125. Véase también Guía de perplejos, capítulo 38, p. 125, donde aparece un fragmento de Exodo, capítulo 33, versículo 13.

15 Q.N.S., p. 117. 
comprendida y analizada. En el afán por poner ejemplos sobre la importancia del calor, Sánchez incluye, como último de ellos, el fragmento de los Hechos de los apóstoles.

En las cosas que carecen de alma hay todavía mayor cambio, mayor diversidad, en la generación y en la corrupción. [...] Sírvate como ejemplo el calor, que, siendo el mismo, engendra, corrompe; blanquea, ennegrece; calienta, enfría [...]. No sin motivo muchos antiguos, en los comienzos de la filosofía, creyeron que el fuego era el principio primero. Con razón Trimegisto llamó Dios al fuego. Y con muchísima razón pudo Aristóteles llamar a Dios calor del cielo, aunque no creyera que el calor del cielo fuese Dios [...]. En efecto, ¿qué puede sugerir mejor que el fuego el poder y la fuerza de Dios Óptimo y Máximo, así como proporcionar una cierta imagen de su inefable divinidad? Él mismo lo dio a entender, al mostrarse por primera vez a su fiel siervo en una zarza ardiente, al guiar a su pueblo amado por el desierto mediante una columna de fuego y al descender en lenguas de fuego sobre la asamblea de sus elegidos. ${ }^{16}$

El carácter contingente de este último fragmento, que es el que pertenece al Nuevo Testamento, parece evidente, pues sin su aparición, el contenido del párrafo no se altera en lo más mínimo. De ahí que cause la impresión de ser un añadido cuyo objetivo bien podría ser el de cubrir las apariencias por la falta de citas que no fueran exclusivas del Antiguo Testamento. Normalmente, en una obra como Quod nihil scitur, no hay ningún elemento superfluo, debido al estilo agudo y directo de su autor, sin embargo, la presencia de esta última frase sacada de los Hechos de los apóstoles no está justificada si no es como un velo sutil para no herir las sensibilidades del catolicismo imperante en la época en que fue escrito. Este fragmento insertado parece tener el objetivo de hacer menos sospechosa la figura de su autor, acusado por la época en que fue escrito de ser un individuo descendiente de judíos, con la estigmatización social y moral que ello suponía en la segunda mitad del siglo XVI. De todo lo expuesto, podemos inferir que Francisco Sánchez debía presentar una aguda influencia del pensamiento judío en el periodo en que el Que nada se sabe fue escrito (alrededor de 1574), pues las pruebas aquí aportadas, con ser interpretables, no dejan mucho margen a la duda respecto a lo forzado de las citas del Nuevo Testamento y lo evidente de la ausencia de la alabanza a la virgen María.

Además de todo lo aquí expuesto, existen otros elementos presentes en la obra del filósofo y médico gallego que lo vinculan directamente con una de las fuentes principales del pensamiento y la filosofía judías: Maimónides. Es éste, médico cordobés, el auténtico vertebrador del pensamiento judío y una fuente 
de la que parece beber directamente Sánchez como a continuación vamos a demostrar.

Entre los elementos de influencia del mundo judío en el tudense, uno de los más importantes, a parte de las citas bíblicas, es el de la relación entre el alma y el cuerpo. Para la teología cristiana, alma y cuerpo pertenecían a esferas muy distintas y con una relación entre ellas prácticamente nula. Frente a esta postura, Sánchez, a lo largo de las páginas de su obra Que nada se sabe, se refiere al alma y al cuerpo de una forma muy distinta, esto es, como parte integrante de un mismo sistema al que completan y perfeccionan: el cuerpo humano. Y resulta que es la tradición judía la que coincide con esta visión del médico gallego. ${ }^{17}$ Así recoge Sánchez esta doctrina de indudables reminiscencias judías:

No tiene sentido decir que el alma entiende, como tampoco lo tiene decir que oye. Es el hombre quien hace lo uno y lo otro, sirviéndose en ambos casos del cuerpo y del alma, y ejecutando cualquier otra cosa con los dos a la vez: no ejecutará nada sin que los dos ayuden, contribuyan y actúen. ${ }^{18}$

Aquí es inevitable recordar la parábola judía del ciego y el cojo, en la que uno no puede funcionar sin la ayuda del otro y solamente cuando están juntos conforman una única entidad. Se refleja así con precisión la perspectiva filosófica que el mundo hebreo tenía de la relación alma-cuerpo. Frente a esta idea se situaría la noción de origen platónico según la cual el alma sería un ente espiritual atrapado en un cuerpo como un pájaro en una jaula.

Sánchez también utilizará la crítica del análisis de los nombres, de clarísima procedencia judía, como la base de la investigación filosófica. El tudense rechaza toda la producción de la filosofía acusándola de ser un laberinto de palabras. En lugar de ocuparse de la investigación directa de la naturaleza, los filósofos han perdido su tiempo preocupados sólo de palabras, de manera que han tejido un mundo ficticio. ${ }^{19}$ Para Sánchez, toda la filosofía de Aristóteles descansa en la definición de nombres, lo cual convierte al filósofo de Estagira en un pensador que confunde naturaleza y palabras. Es aquí donde surge otro nexo de unión entre Sánchez y la filosofía judía. La tradición filosófica sefardí no reconocía el vínculo entre lenguaje y naturaleza; el lenguaje estaría fundado sobre la convención, no en la naturaleza. Por consiguiente el significado de las palabras no refleja la naturaleza real de las cosas. Del mismo modo, Sánchez mantendrá que las palabras no poseen la facultad de reflejar la naturaleza de las cosas y, puesto que los distintos lenguajes son arbitrarios, las palabras que

17 José Faur, op. cit., p. 97.

18 Q.N.S., p. 211.

19 Q.N.S., p. 55. 
los conforman no pueden constituir una fuente fiable de información sobre la verdadera esencia de los objetos a los que se refieren. ${ }^{20}$

Como es fácil de observar, las similitudes de la filosofía expuesta por Francisco Sánchez en su obra Que nada sabe con el pensamiento judío son incontrovertibles. Las analogías son claras y el hecho de que perteneciera a un entorno de origen judío es una indicación más de hacia dónde apuntan estas sospechas. La conclusión que estas páginas nos permiten alcanzar es que la filosofía judía ha ocupado un lugar más importante de lo que tradicionalmente se ha pensado en la historia del pensamiento, siendo un deber de la crítica actual el tratar de reconocer esta influencia. Casi con total probabilidad podemos establecer que Sánchez escribió sus primeras obras bajo la égida intelectual del judaísmo y su filosofía.

Manuel Bermúdez Vázquez. Departamento de Ciencias Sociales y Humanidades, Facultad de Filosofía y Letras, Universidad de Córdoba.

Publicaciones recientes:

«The transmisión and recovery of pyrrhonism», Elenchos, XXIV, 2003, pp. 517-518.

«Elementos de la filosofía de Maimónides en el Quod nihil scitur de Francisco Sánchez», Maimónides y el pensamiento medieval. IV Congreso Nacional de filosofía medieval, Actas, Córdoba, 2004 (en prensa).

La recuperación del escepticismo en el Renacimiento como propedéutica de la filosofía de Francisco Sánchez, Tesis doctoral, Fundación Universitaria Española, Madrid, 2006.

Líneas de investigación:

Historia de la filosofía, escepticismo.

Dirección postal:

C/ Valenzuela, nº 8, Lucena, 14900, Córdoba.

Dirección electrónica: manuelbeva@hotmail.com

20 Q.N.S, p. 134. 